\title{
Porous multi-junction thin-film silicon solar cells for scalable solar water splitting
}

\author{
Christos Trompoukis ${ }^{\mathrm{a}, \mathrm{b}, *}$, Aimi Abass ${ }^{\mathrm{c}}$, Jan-Willem Schüttauf ${ }^{\mathrm{d}}$, Tom Bosserez ${ }^{\mathrm{b}}$, Jan Rongé ${ }^{\mathrm{b}}$, \\ Johan Lauwaert $^{\mathrm{e}}$, Johan A. Martens ${ }^{\mathrm{b}}$, Roel Baets ${ }^{\mathrm{a}}$ \\ a Ghent University, Photonics Research Group, iGent, Technologiepark Zwijnaarde 15, 9000 Ghent, Belgium \\ ${ }^{\mathrm{b}}$ KU Leuven, Centre for Surface Chemistry and Catalysis, Celestijnenlaan 200F, 3001 Leuven, Belgium \\ ${ }^{\mathrm{c}}$ Karlsruhe Institute of Technology (KIT), Institute of Nanotechnology, 76021 Karlsruhe, Germany \\ d Swiss Center for Electronics and Microtechnology (CSEM), PV Center, Rue Jaquet-Droz 1, Neuchâtel, Switzerland \\ e Ghent University, Department of Electronics and Information Systems, iGent, Technologiepartk Zwijnaarde 15, 9000 Ghent, Belgium
}

\section{A R T I C L E I N F O}

\section{Keywords:}

Solar water splitting

Thin-film silicon solar cells

Hydrogen storage

Porous solar cells

\begin{abstract}
A B S T R A C T
Monolithic solar water splitting devices implemented in an integrated design approach, i.e. submerged in the electrolyte, pose a significant limitation when it comes to up-scaling. The ion transport distances around the monolith are long and consequently, the ionic Ohmic losses become high. This fact turns out to be a bottleneck for reaching high device efficiency and maintaining optimum performance upon up-scaling. In this paper, we propose a new device design for integrated monolithic solar water splitting based on porous multi-junction silicon solar cells. Simulation results highlight that porous monoliths can benefit from lower ionic Ohmic losses compared to dense monoliths for various pore geometries and monolith thicknesses. In particular, we show how micrometer scale pore dimensions could greatly reduce Ohmic losses, thereby minimizing overpotentials. A square array of holes with a diameter of $20 \mu \mathrm{m}$ and a period of $100 \mu \mathrm{m}$ was fabricated on single-junction and multi-junction amorphous and microcrystalline silicon solar cells. A small impact on the open circuit voltage $\left(\mathrm{V}_{\mathrm{oc}}\right)$ and short circuit current density $\left(\mathrm{J}_{\mathrm{sc}}\right)$ was obtained, with porous triple junction solar cells reaching $\mathrm{V}_{\mathrm{oc}}$ values up to $1.98 \mathrm{~V}$. A novel device design is proposed based on porous triple-junction silicon-based solar cells.
\end{abstract}

\section{Introduction}

Electrification offers a great potential to enable the de-carbonisation of energy [1]. According to several studies, a sustainable energy system based on $100 \%$ renewable energy sources, of which the majority is wind and solar, should be possible $[2,3]$. However, the intermittent nature of wind and solar is a bottleneck for large-scale grid implementation. In order to balance generation and demand, the storage of produced energy is imperative. The storage of renewable electricity in the form of chemical bonds, such as hydrogen $\left(\mathrm{H}_{2}\right)$, could fill in the gap and empower a sustainable energy system [4]. Other than storage, green hydrogen could play an important role in such a renewable energy system for the de-carbonisation of transportation, building heating and as fuel for industrial use.

Among the many different techniques which can achieve the conversion of water and sunlight into hydrogen (e.g. PV-electrolysis, thermal conversion and molecular artificial photosynthesis), photoelectrochemical (PEC) water splitting is a promising approach [5-8]. Apart from the properties and performance of the involved materials in a PEC device (photoabsorbers with optimal band gaps, catalysts, protective coatings, etc.) the cell design is a key element not only for enabling high solar to hydrogen efficiency (STHE, i.e. the ratio of the available chemical energy in the generated hydrogen to the incident solar energy), but also for maintaining those high values when upscaling for large-scale implementation.

The majority of lab scale PEC demonstrators employ the wired configuration, shown in Fig. 1a. With this design, Khaselev et al. have demonstrated a device reaching an STHE of 16.4\% [9]. However, their approach includes expensive III-V materials which are too costly for terrestrial applications. In a cost-effective approach based on triple junction silicon solar cells, the same group showed a device reaching $7.8 \%$ [9], while more recently Urbain et al. reported a device reaching an STHE of $6.8 \%$ [10]. In order to reduce cost, the wireless monolithic design (Fig. 1b) has been proposed. With this design, Reece et al. reported a $2.5 \%$ efficient PEC device [11]. They attributed the lower STHE value compared to their wired reference device, which reached an STHE of $4.7 \%$, to the high Ohmic losses due to long ion transport distances around the monolith. In fact, the ionic Ohmic losses are 


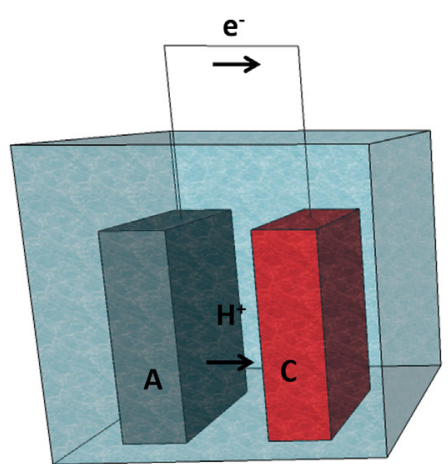

a) Wired design

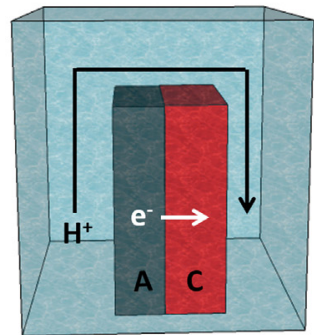

b) Dense wireless monolith

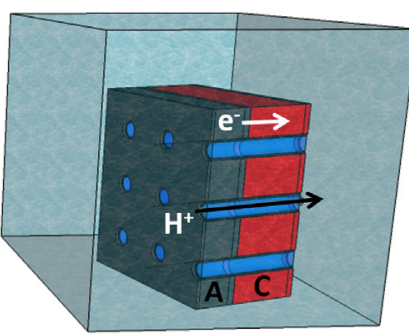

c) Porous wireless monolith
Fig. 1. Photoelectrochemical cell configurations for monolithic integrated solar water splitting: (Photo)anode (A) and (Photo) cathode (C) in a) a wired configuration where the ionic transport distance is defined by the distance between the two photoelectrodes, usually in the $\mathrm{cm}$ range, b) the monolithic wireless approach where the ionic transport distance is defined by the thickness and surface area of the monolith and c) porous monolithic wireless configuration where through plane pores act as ionic shortcuts and the ionic transport distance can reach a few tens of $\mu \mathrm{m}$. higher in a wireless than a wired design (electronic conductivities are much higher than the ionic conductivities), thus limiting the efficiencies [12]. However, this approach offers an alternative to satisfy the efficiency/cost trade-off [4]. Towards this direction of integrated monolithic devices, the idea of porosity (Fig. 1c) for solar water splitting has been mentioned conceptually $[7,12]$, has been demonstrated in simplified monoliths [13], while theoretical works have touched upon the concept of ionic shortcuts $[14,15]$. In particular, as discussed by Haussener et al. [14], for monolithic PEC configurations, small electrode lengths and thin separation distances lead to reduced Ohmic losses because of short ion transport distances. For an operation sustained by water vapor, a monolith width of less than $300 \mu \mathrm{m}$ is proposed for reducing the overpotential to values lower than $100 \mathrm{mV}$, even for a thickness of $1 \mu \mathrm{m}$ [15]. According to such design guidelines, through plane pores incorporated on the monolith could act as ionic shortcuts, minimizing Ohmic losses. To further investigate this idea, simplified perforated monoliths were fabricated experimentally, and their Ohmic losses were evaluated. As shown by Bosserez et al. [13], the Ohmic losses were kept at acceptable levels (below $100 \mathrm{mV}$ of overpotential) provided a pore spacing less than $1 \mathrm{~mm}$ and electrolytes at extreme $\mathrm{pH}$ values.

In this paper, we propose a novel device design based on porous multi-junction thin-film silicon solar cells. In such a design, the multijunction solar cells could provide the required high voltage values for the water splitting operation while micron-scale porosity would act as a shortcut for ions, minimizing their transport distances and thus, the respective Ohmic losses. Therefore, the achieved STHE values could be maintained upon up-scaling for cost-reduction. Our intention is to provide a new design approach, based on the concept of micron-scale porosity, so as to trigger discussions and activities within the scientific community. Such a paradigm shift in the device design of monolithic PEC cells could hopefully help to further develop new designs deviating from more conventional concepts.

In the following sections, we will present our simulation results on porous monoliths so as to highlight the potential of this approach. Furthermore, we will present the experimental fabrication of micronscale pores on single-junction and multi-junction thin-film silicon solar cells and we will discuss the impact of introducing porosity on their performance. Finally, we will discuss the perspectives of this approach and present our envisioned device design.

\section{Material and methods}

In order to investigate the potential of the concept of porous PEC monoliths, 2D electrochemical (EC) simulations were performed using the Tertiary Current Distribution electrochemistry module of COMSOL Multiphysics [16]. In our simulations, the system was considered to be periodic in the horizontal direction with monoliths of various periodicity $(P)$, pore width $(w)$ and thickness $(t)$ operating at electrolytes with different $p H$, as shown in Fig. 2. The reaction kinetics at the anode and cathode sides were considered to follow the Butler-Volmer equation. The pore sidewalls were considered to be perfectly insulated and do not act as reaction sites. In order to focus only on the effect of the geometrical parameters on the monolith's performance, we restricted the simulations on state-of-the-art high performing reaction kinetics considering Pt electrode parameters for the cathode and $\mathrm{RuO}_{2}$ parameters for the anode.

The current flows in the EC system through ion transport in the electrolyte were modelled with $J_{l}=F \sum_{i=1}^{n} z_{i}\left(-D_{i} \nabla c_{i}-z_{i} \mu_{m, i} F c_{i} \nabla \phi_{l}\right)$, where $J_{i}$ is the electrolyte current, $F$ is the Faradaic constant $z_{i}$ is the valence charge of the considered ionic species, $D_{i}$ is the diffusion coefficient, $c_{i}$ is the concentration of ionic species, $\mu_{m, i}$ is the effective mobility of the ionic species, $\Phi_{i}$ is the electrolyte potential, and the $\mathrm{i}$ sub-index refers to contribution from a specific ionic species. We assumed that there is no electrolyte flow and thus the current transport is only due to ionic charge's electric field driven transport (migration) and diffusion. We considered sulphuric acid $\left(\mathrm{H}_{2} \mathrm{SO}_{4}\right)$ as the electrolyte at various $\mathrm{pH}$, with only $\mathrm{H}^{+}$and $\mathrm{HSO}_{4}{ }^{-}$ions in the electrolyte. Transport of ionic species through the ion exchange membrane were assumed to follow the same equation but for Nafion's corresponding diffusion coefficients. The ionic species concentration in the electrolyte follows the electroneutrality condition $\sum_{i=1}^{n} z_{i} c_{i}=0$. In our calculations, the electrodes were considered to be perfectly conducting, the gas species were considered to be immediately extracted upon generation at the electrodes and crossover effects were ignored. We always ensured that the top and bottom computational domain boundaries were sufficiently far away such that there was zero current at these boundaries. The EC current was calculated by integrating the reaction current density at the anode or cathode active surface and normalizing it to the total surface, which includes the membrane area where no water splitting reaction occurs. All relevant physical constants were taken from the contribution of Haussener et al. [14].

The thin-film silicon solar cells were deposited on glass carriers in a medium-sized $\left(40 \times 50 \mathrm{~cm}^{2}\right)$ single-chamber plus load lock R\&D reactor by plasma enhanced chemical vapor deposition (PECVD). All solar cells were made in a $\mathrm{p}-\mathrm{i}-\mathrm{n}$ configuration, meaning that the respective layers ( $\mathrm{p}, \mathrm{i}$ and $\mathrm{n}$ ) were deposited in that order. The single and tandem solar cells were used in a superstrate configuration while the triple junction solar cells were used in the substrate configuration. The absorber layers consisting of hydrogenated amorphous silicon (a-Si:H) have a thickness of $500 \mathrm{~nm}$ for the single junction cells while for the tandem and triple junction cells the a-Si:H thickness is $130 \mathrm{~nm}$ and $500 \mathrm{~nm}$ for the top and second layers, respectively. The microcrystalline silicon cells ( $\mu \mathrm{c}-\mathrm{Si}: \mathrm{H}$ ) have an absorber layer thickness in excess of $1 \mu \mathrm{m}$. All layers were deposited from a gas mixture including $\mathrm{SiH}_{4}$ and $\mathrm{H}_{2}$. For the p-type layers, trimethylborane $\left(\mathrm{TMB}=\mathrm{B}\left(\mathrm{CH}_{3}\right)_{3}\right)$ was used as the dopant gas, whereas for the n-type layers phosphine $\left(\mathrm{PH}_{3}\right)$ was used. The $2 \mu \mathrm{m}$ thick transparent conductive contacts consist of boron doped zinc oxide ( $\mathrm{ZnO}: \mathrm{B}$ ), and were fabricated by low pressure chemical vapor deposition (LPCVD) in a home-made system from a gas mixture of diethyl-zinc $\left(\mathrm{Zn}\left(\mathrm{C}_{2} \mathrm{H}_{5}\right)_{2}\right), \mathrm{H}_{2} \mathrm{O}$ and diborane $\left(\mathrm{B}_{2} \mathrm{H}_{6}\right)$. 


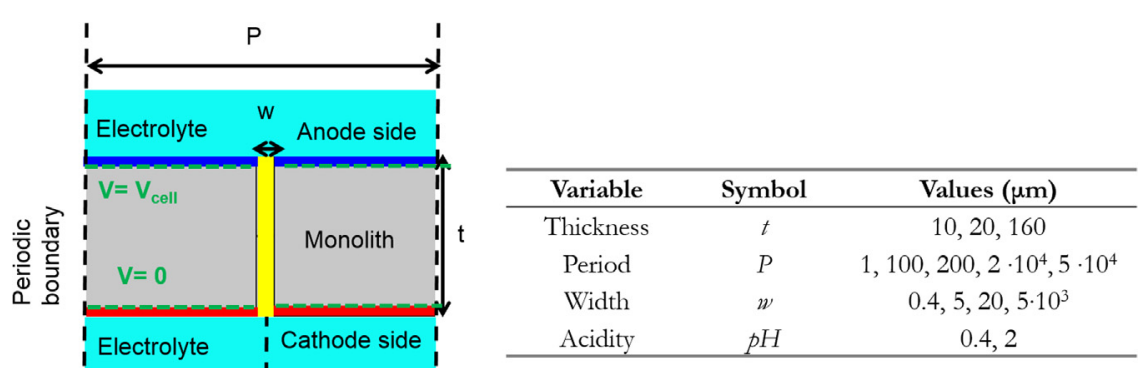

Fig. 2. 2D simulated photoelectrode-EC system (left) and values of the dimensions of the investigated design monoliths (right).

A square array of cylindrical holes with a period of $100 \mu \mathrm{m}$ and a pore diameter of $20 \mu \mathrm{m}$ was fabricated by optical lithography and dry etching. For the silicon part of the cells, reactive ion etching (RIE) was used while for the $\mathrm{ZnO}: \mathrm{B}$ layers inductively coupled plasma (ICP) etching was preferred over wet etching $\left(\mathrm{HF}\right.$ or $\left.\mathrm{NH}_{4} \mathrm{Cl}\right)$ due to minimal under-etch and therefore less impact on the film's sheet resistance. The porous and non-porous solar cells were characterized by current density - voltage $(\mathrm{J}-\mathrm{V})$ measurements at $25^{\circ} \mathrm{C}$ under AM1.5 filtered 1-sun illumination using a single beam Xenon lamp solar simulator from Oriel. For the porous solar cells that the photoactive material has been etched, the current density has been normalised to take into account the removed area.

\section{Results}

\subsection{Effect of porosity on electrochemical performance (simulation results)}

The goal is to check the influence of geometry on the EC behaviour of the system and compare porous and dense monoliths with respect to
Ohmic losses. The J-V characteristics for various porous monolithic geometries are shown in Fig. 3. We first depict the influence of monolith thickness and pore width for a constant electrolyte $\mathrm{pH}$ of 2 (Fig. 3a). Three different thicknesses were considered: 10, 20 and $160 \mu \mathrm{m}$. The $10 \mu \mathrm{m}$ thickness corresponds to a relevant thickness of the full material stack (silicon based photoabsorbers and transparent conductive oxides) of a multi-junction thin-film solar cell. This case represents the design where the solar cell is located on top of a highly porous and catalytically active substrate and therefore the effective distance for the ions is that of the solar cell. The $160 \mu \mathrm{m}$ case is that of a low resistivity silicon wafer $(\sim 150 \mu \mathrm{m}$ thick) on top of which the thinfilm multijunction solar cell $(\sim 10 \mu \mathrm{m}$ thick) is deposited. Finally, the $20 \mu \mathrm{m}$ thickness corresponds to the case of the thin-film multijunction solar cell $(\sim 10 \mu \mathrm{m})$ on top of an ultrathin $(\sim 10 \mu \mathrm{m})$ single-crystal silicon foil [17], a device with a thickness that could be processed using standard equipment, as already demonstrated for solar cell devices $[17,18]$.

We can first focus on the $10 \mu \mathrm{m}$ thickness case (black curves of Fig. 3a) and the performance of three different pore geometrical cases.
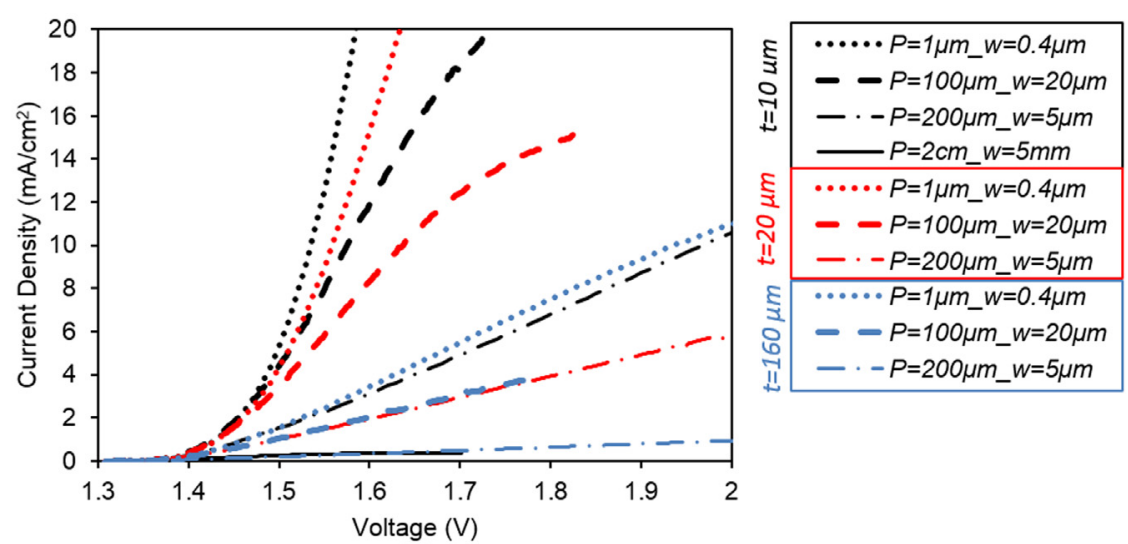

(a)
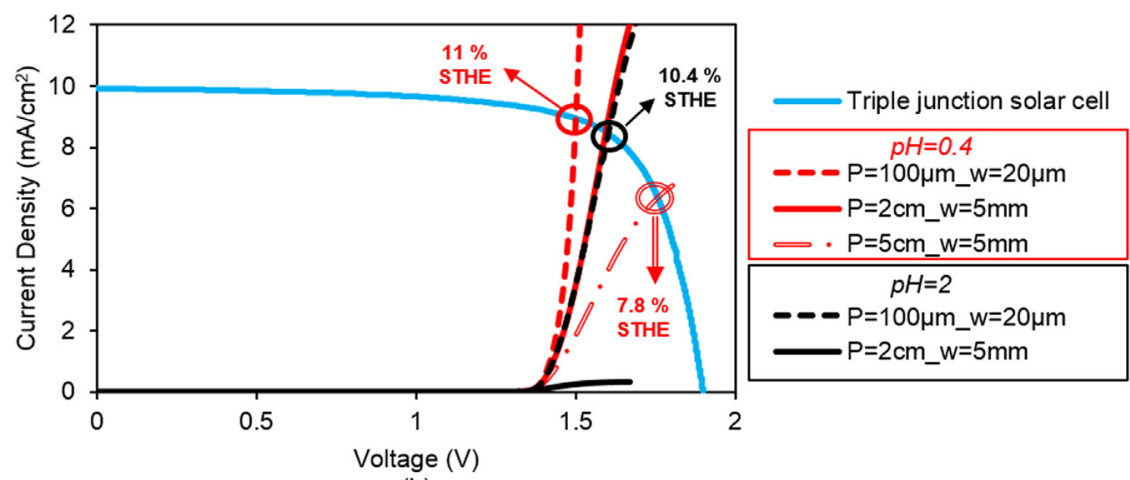

(b)
Fig. 3. Electrochemical J-V curves simulated with COMSOL Multiphysics for (a) various pore geometries and monolith thickness at an electrolyte $\mathrm{pH}$ of 2 and (b) selected porous and dense monolith geometries at $\mathrm{pH}$ of 0.4 and 2 superimposed with the $\mathrm{J}-\mathrm{V}$ curve of the best reported multi-junction silicon solar cell [24]. (For interpretation of the references to color in this figure, the reader is referred to the web version of this article.). 
These pore geometrical cases represent different regimes and their performance is benchmarked with respect to dense monoliths $(2 \mathrm{~cm}$ and $5 \mathrm{~cm}$ electrode width separated by $5 \mathrm{~mm}$ ion exchange membrane) which is used as a reference. The dotted J-V curve represents the EC characteristics of a porous monolith where the ion transport pore geometry and distribution is in the size regime comparable to the wavelength of light, thus enabling photonic light trapping. In particular, we considered a period of $1 \mu \mathrm{m}$ and a pore width of $400 \mathrm{~nm}$. With such period and width, the pores essentially function as a diffraction grating or photonic crystal system, which may also enhance light absorption based through oblique angle scattering that increases the optical path length of light in the solar cell $[19,20]$. Solar cell devices employing a photonic assisted light trapping scheme have been already proposed and realized in thin solar cells [21]. However, it should be mentioned that the chosen period and pore width are not optically optimal but are rather used here as a first demonstration. For further fine tuning optical simulations are required. The dashed-dotted J-V curve represents the case where the size scale is much larger with a period of $200 \mu \mathrm{m}$ and a pore width of $5 \mu \mathrm{m}$. This configuration corresponds to a design where $200 \mu \mathrm{m}$ wide photoelectrode "islands" are separated by $5 \mu \mathrm{m}$ gaps similar to a micro-fluidic approach [22]. In such system, the proton ions formed at the centre of the "island" would have to travel a significantly longer distance and thus suffer from more effective electrolyte resistance. As a result, the $\mathrm{J}-\mathrm{V}$ curves of the two cases have significant differences, with the latter one requiring a higher voltage for an operation at a specific current density. For example, for an operation at $10 \mathrm{~mA} / \mathrm{cm}^{2}$, the first small scale photonic approach requires an overpotential of $\sim 300 \mathrm{mV}$ to drive the water splitting reactions while the large scale "islands" requires an overpotential as high as $770 \mathrm{mV}$. Finally, an intermediate case is represented by the dashed J-V curve with a period of $100 \mu \mathrm{m}$ and a pore width of $20 \mu \mathrm{m}$. This configuration presents a scenario, where conventional patterning techniques such as UV lithography, could be used for its realization. High current densities can be achieved for a small overpotential deficit compared to the much stricter photonic case. All porous configurations mentioned above have EC J-V characteristics which clearly outperform the non-porous reference case (solid J-V curve). For the non-porous monolith, the ionic transport distances are so large that mass transport limitations of the ions dominate the $\mathrm{J}-\mathrm{V}$ characteristic, which result in a flattening of the $\mathrm{J}-\mathrm{V}$ characteristic beyond $1.5 \mathrm{~V}$ of applied voltage (black solid line curve, Fig. 3a and b). As a result, the current densities are restricted to values lower than $1 \mathrm{~mA} / \mathrm{cm}^{2}$. For a pore period of $100 \mu \mathrm{m}$, width of $20 \mu \mathrm{m}$ and $\mathrm{pH}$ of 2 (red dash curve Fig. 3a), one can also see the onset of the mass transport limitations at $\sim 1.75 \mathrm{~V}$ though a sufficiently large current density in the electrolyte is already obtained.

Results for two more thicknesses (i.e. $160 \mu \mathrm{m}$ and $20 \mu \mathrm{m}$ ) are shown in Fig. 3a with red and blue colour, respectively. The same trend as for the $10 \mu \mathrm{m}$ case is seen for the different pore geometries with the extra overpotential penalty which has to be paid for the additional thickness through which ions have to travel (curves of similar colour but different dash type should be compared here). It should be mentioned that the J$\mathrm{V}$ curves of the dense monoliths for those two thicknesses were lower than the $10 \mu \mathrm{m}$ case and they are omitted from the figure for better clarity. Overall, the thinner the monolith is, the lower the Ohmic losses get (curves of different colour but similar dash type should be compared here). However, practical limitations such as the ability to process thin substrates should be taken into account for defining the most relevant thickness.

The electrolyte $p H$ case of 0.4 was also investigated. As shown in Fig. $3 \mathrm{~b}$, porous and dense monoliths operating in an electrolyte with a $p H$ of 0.4 can achieve better $\mathrm{J}-\mathrm{V}$ performance with lower Ohmic losses compared to an electrolyte with a $\mathrm{pH}$ of 2 (red vs black curves). However, we should note here that for similar changes in the $\mathrm{pH}$ of the electrolyte, the device stability has been shown to be significantly affected [23]. Therefore, by incorporating pores, we could relax the requirements for operation in electrolytes at extreme $p H$ which corrode the photoelectrodes compromising the device lifetime and stability. This can be seen by the similar J-V behaviour which was obtained for the dense monolith with an electrode of $2 \mathrm{~cm}$ at $p H 0.4$ (solid red) and the porous monolith at $p H 2$ (dashed black). Nevertheless, when it comes to upscaling, a dense monolith's Ohmic losses will further increase when its size increases thus limiting the STHE values that could be achieved. This is clearly highlighted when comparing the dense monoliths with electrode dimensions of 2 and $5 \mathrm{~cm}$. On the contrary, since porosity actually offers no restrictions in up-scaling, the achieved STHE values for porous monoliths could be maintained when up-scaling the device.

In order to show the potential of the porosity concept with respect to the STHE values that could be achieved, we consider the best reported triple junction thin-film silicon solar cell [24]. We can pinpoint the operating point by superimposing the $\mathrm{J}-\mathrm{V}$ curve of the triple junction PV [25] with the simulated EC J-V curves for the case of a monolith of $20 \mu \mathrm{m}$ in thickness. The operating point would then be at the intersection of the two J-V curves (Fig. 3b). For this discussion, no device degradation due to the incorporation of the pores is considered while a Faradaic efficiency of $100 \%$ is assumed. As highlighted in Fig. 3b, an STHE of $11 \%$ should be possible (red circle highlighting the operating point) for a porous monolith at $p H=0.4$. The STHE decreases slightly to $10.4 \%$ (black circle highlighting the operating point) when a higher $\mathrm{pH}$ electrolyte value is considered. For the dense monoliths, the Ohmic losses at $p H=0.4$ increase when increasing the monolith size from 2 to $5 \mathrm{~cm}$ resulting in a decrease in STHE from $10.4 \%$ to $7.8 \%$. While the STHE will further decrease for bigger dense monoliths even at extreme $p H$, porous monoliths could be upscaled without limitations in size. Therefore, a porous monolith even in relaxed $p H$ conditions offers the potential for better STHE without limitation to upscaling.

\subsection{Impact of porosity on the $P V$ performance (experimental results)}

On the device level, etching a solar cell to introduce corrugations can be expected to have a strong impact on the quality of the photoactive material [26], affecting the cell's overall performance, thereby compromising the achievable STHE. Therefore, the most appropriate monolithic PV technology is the multi-junction thin-film silicon solar cell with amorphous silicon (a-Si) and/or microcrystalline silicon ( $\mu \mathrm{c}$ $\mathrm{Si}$ ) as the photoactive layers. On one hand, such multi-junction solar cells can provide high voltage. On the other hand, the involved photoactive materials are less vulnerable to damage compared to their crystalline silicon counterparts (both having intrinsically short diffusion lengths) and can be easily optimised in order to ensure strong absorption and optimal usage of the solar spectral range.

In order to investigate to what extent porosity affects the solar cell operation we focused on a-Si, $\mu \mathrm{c}-\mathrm{Si}$ single-junction as well as multijunction (tandem and triple junction) solar cells. Each step of the pore fabrication process has an impact on the device performance and its respective parameters, i.e. short circuit current $\left(\mathrm{J}_{\mathrm{sc}}\right)$, open circuit voltage $\left(V_{o c}\right)$, fill factor (FF) and efficiency $(\eta)$. To highlight this, we show in Fig. 4 the illuminated $\mathrm{J}-\mathrm{V}$ scans for the case of an a-Si tandem solar cell (500 $\mathrm{nm}$ bottom a-Si/130 $\mathrm{nm}$ top a-Si).

The first ZnO:B ICP etch, which is actually taking place on the rear of the solar cell, has an impact mainly on the collection of photogenerated carriers. In particular, because of an increase in the sheet resistance of the $\mathrm{ZnO}: \mathrm{B}$ film, the FF decreases. The subsequent step of RIE on a-Si causes a slight decrease in all parameters. By etching the photoactive material, extra recombination sites (unpassivated dangling bonds that extend inside the pores as a result of the etching process and the respective surface area enhancement) are introduced, thus affecting the achievable Voc values. However, the Voc was only slightly affected despite the fact that we etched through the photoactive material. Finally, for the porous solar cell, a further decrease in all cell parameters is observed with a decrease in $\mathrm{V}_{\text {oc }}$ as low as $63 \mathrm{mV}$.

The same behaviour was observed for the rest of the studied solar 


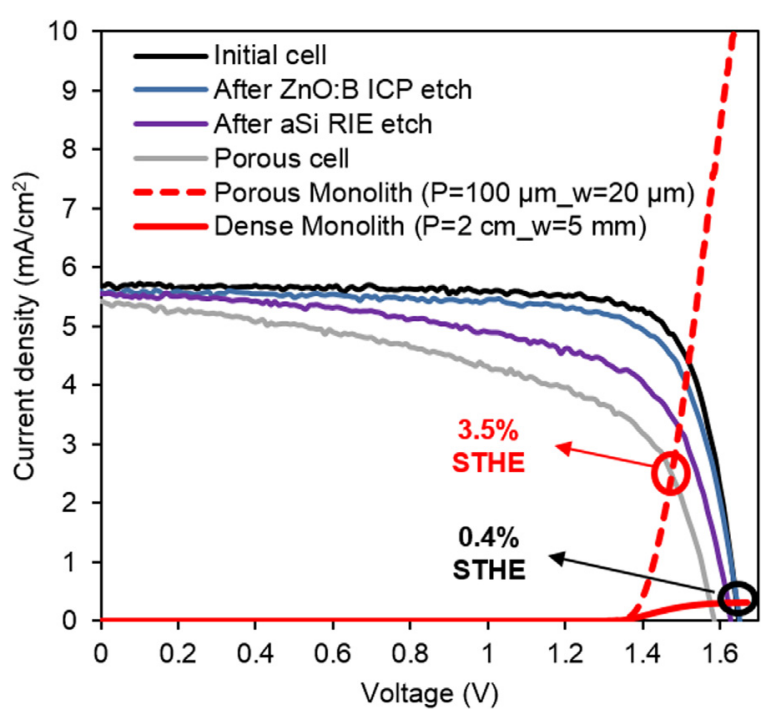

Fig. 4. Impact of porosity on the solar cell performance: illuminated current density - voltage scans for a-Si based tandem solar cells without pores (black curve), after etching the rear $\mathrm{ZnO} \mathrm{B}$ layer (blue), after etching the a-Si layers (purple) and with pores through the whole cell stack (gray). The EC J-V curves for the dense $(2 \mathrm{~cm}$ electrode width separated by $5 \mathrm{~mm}$ ion exchange membrane) and porous (period of $100 \mu \mathrm{m}$ and pore width of $20 \mu \mathrm{m}$ ) monoliths are included in order to highlight the respective achievable STHE. (For interpretation of the references to color in this figure legend, the reader is referred to the web version of this article.)

cell devices. Plotting the values of each solar cell parameter before and after introducing porosity, we can notice some trends shown in Fig. 5. The impact of porosity is more pronounced on the $\mu \mathrm{c}-\mathrm{Si}$ than on the a-Si solar cells. On one hand, while $2.5 \mathrm{~mA} / \mathrm{cm}^{2}$ were lost when introducing porosity on the $\mu \mathrm{c}$-Si solar cells, the loss was restricted to below $1 \mathrm{~mA}$ / $\mathrm{cm}^{2}$ for the porous a-Si solar cells. On the other hand, the defects introduced on the photoactive material by the implementation of porosity resulted in a higher decrease in $\mathrm{V}_{\mathrm{oc}}$ for $\mu \mathrm{c}$-Si solar cells $(40 \mathrm{mV})$ compared to the a-Si cells $(16 \mathrm{mV})$. The shorter diffusion lengths for the a-Si solar cells compared to the $\mu \mathrm{c}-\mathrm{Si}$ solar cells could be responsible for such a different impact on $\mathrm{V}_{\text {oc }}$ as fewer generated carriers reach the pore sidewalls which act as recombination sites. The increased amount of recombination centres, apart from the aforementioned impact on Voc, similarly leads to a decrease in FF. Finally, while the impact of porosity on the efficiency of $\mu \mathrm{c}-\mathrm{Si}$ solar cells was high (relative difference of $29 \%$ ), a-Si solar cells suffer only from a limited impact (relative difference of $14 \%$ ).

For the multi-junction solar cells, two cases were considered: a tandem $(500 \mathrm{~nm}$ a-Si bottom/ $130 \mathrm{~nm}$ a-Si top) cell and a triple $(1 \mu \mathrm{m}$ $\mu \mathrm{c}-\mathrm{Si}$ bottom/500 $\mathrm{nm}$ a-Si middle/130 $\mathrm{nm}$ a-Si top) cell. The decrease in performance was smaller for the a-Si tandem cell compared to the triple junction cell. Nonetheless, the triple junction solar cell had only a marginal decrease in $\mathrm{V}_{\mathrm{oc}}$ of $162 \mathrm{mV}$ ( $8 \%$ relative difference, from an initial value of $2145 \mathrm{mV}$ to $1983 \mathrm{mV}$ after the implementation of the pores), highlighting the minimal material degradation when implementing pores in the device. Similar to the $\mathrm{V}_{\mathrm{oc}}$, the $\mathrm{J}_{\mathrm{sc}}$ value of the porous triple junction solar cell was only $7 \%$ lower compared to the non-porous cell. It should be mentioned here that the low $\mathrm{J}_{\mathrm{sc}}$ values obtained for the triple junction solar cells is attributed to a non-optimal current matching because of a thinner $\mu \mathrm{c}$-Si layer. For both tandem and triple junction cells, the FF was the most affected parameter. The different impact on the FF among the single junction and multijunction solar cells could be explained by the fact that the a-Si top cell in the multi-junction cells is thinner $(\sim 130 \mathrm{~nm})$ than the respective a-Si single junction cell $(500 \mathrm{~nm})$. Although for both single-junction and multijunction cells the electronic defects at the edges of the pores might provide a conductive path between both contacts, thereby partially shunting them, the top cell in the multi-junction cells is very thin thus making the effect more pronounced. In fact, the multi-junction cells had a decreased shunt resistance compared to the single-junction cells. Nevertheless, such a high $\mathrm{V}_{\text {oc }}(1983 \mathrm{mV})$ achieved for the porous triplejunction solar cells offers some degrees of freedom for designing a solar water splitting porous device. In particular, since any potential which is higher than the operating potential is actually not contributing to the increase of the STHE, a device with lower $\mathrm{V}_{\text {oc }}$ could be afforded. Considering the aforementioned results, a triple-junction solar cell could be specifically designed for the application of porous solar water splitting [23,27], targeting to achieve a better trade-off between photovoltage - photocurrent and to mitigate the degradation in FF.

Finally, despite the device degradation from the incorporation of holes, the benefit of our approach can be easily highlighted by focusing on the expected STHE values, i.e. the operating point resulting from the superposition of the simulated EC J-V results with the experimental J-V PV curves (Fig. 4). In particular, the impact on the achievable STHE due to the loss in solar cell device performance (red circle as the operating point of the porous monolith in Fig. 4) is smaller than the impact on the achievable STHE due to the Ohmic losses from the long ion transport distance around the dense monolith (black circle as the operating point of the non-porous monolith in Fig. 4). It should be noted that the absolute numbers of the STHE discussed here are only indicative for the specific case of the tandem a-Si based solar cell. The reason that the STHE values mentioned in Fig. 4 are lower compared to the STHE values mentioned in Fig. $3 \mathrm{~b}$ is related to the difference in the IV of the involved solar cells. Compared to the tandem a-Si solar cell shown in Fig. 4, the triple junction cell such as the one in Fig. 3b results in a higher Voc value and a better current matching leads to a higher Jsc value thus resulting in higher STHE values. In general, differences between theoretical limiting efficiencies and the STHE values of practical devices are due to the properties of the involved materials as well as their optimal combination, which defines the performance of the initial device [28], while for porous devices the degree of device degradation after the incorporation of pores would further restrict the final STHE values. Starting from a highly performing multi-junction silicon solar cell such as the record efficiency cell reported by Sai et al. [24], an STHE value of around 7-8\% could be achieved assuming a similar degradation as the one reported here. While such STHE is comparable to state of the art thin-film silicon based monolithic devices at a miniature scale (device demonstrators are usually less than a $\mathrm{cm}$ in size), the approach of porous multijunction solar cells offers the advantage of upscaling the device without any limitation in size. Possible ways to decrease the difference between theoretical and practical devices include i) designing of a solar cell for an operation in a solar water splitting device with a relevant current-voltage trade-off [28] and ii) the restoration of the solar cell degradation by treatments, such as hydrogenation, employed after the pore fabrication process.

\section{Discussion and perspectives}

Although the PEC approach is conceptually simple and elegant, it has proven challenging to reach practical implementation since it combines complex mechanisms involving light-matter interaction, semiconductor physics and electrocatalysis. It is for this reason that ever since the highest efficiency device demonstration [9], endeavours to reach a similar efficiency with a stable material system have had limited progress, even if a lot of research has been dedicated to improving the involved processes. To date, not only is there no system that surpasses the $16.4 \%$ efficiency mark with a low cost approach as well as long and stable device operation, but also reported devices are still far from the theoretical upper limits in efficiency [28]. Moreover, scalability is too often overlooked in existing device architectures.

The proximity of PEC solar water splitting to the much more mature field of PV could be an advantage. The learning curve of PV has driven 

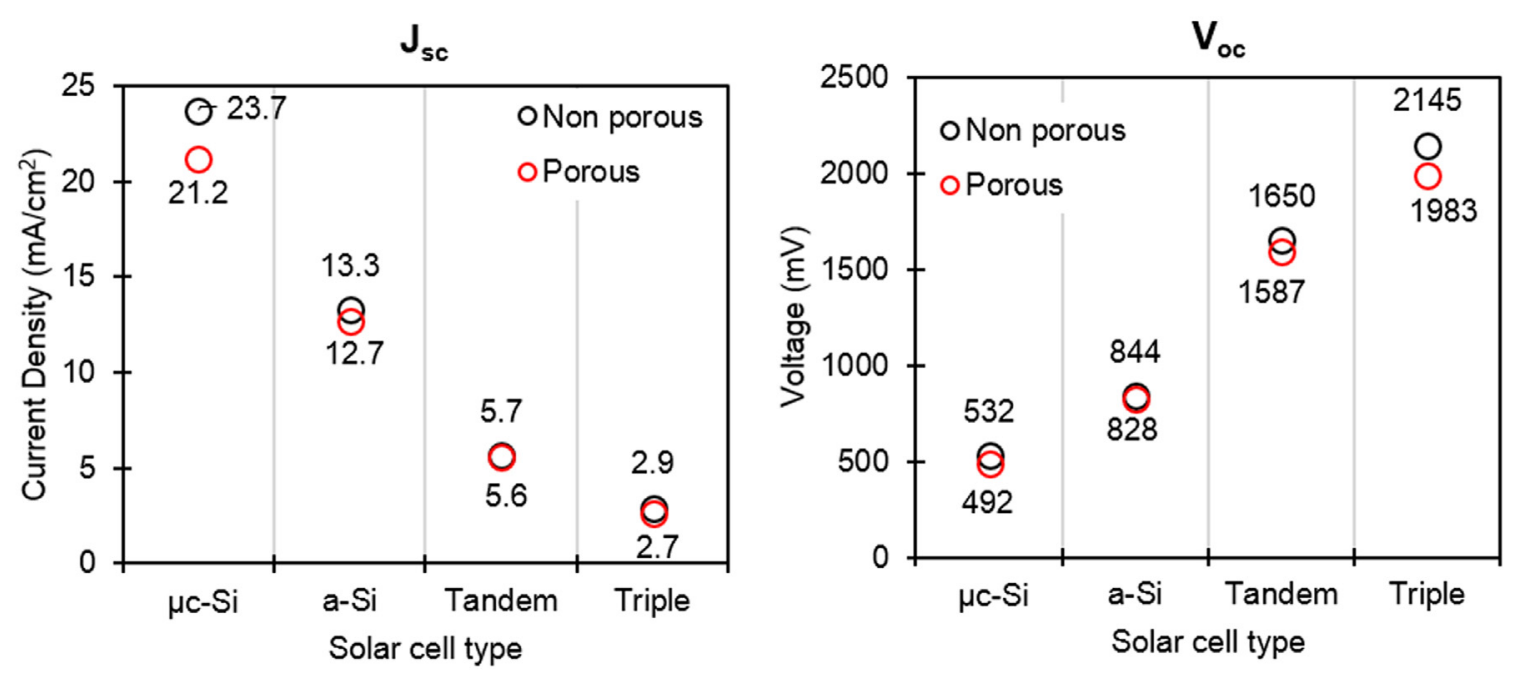

FF

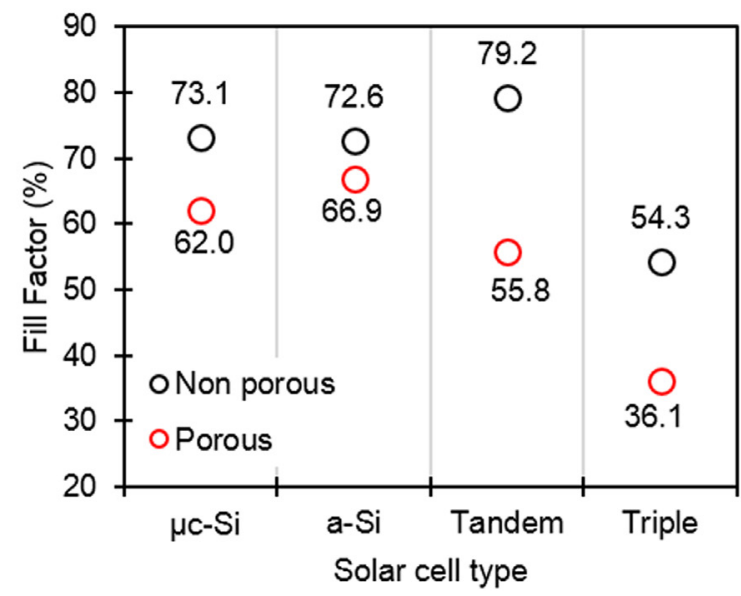

$\eta$

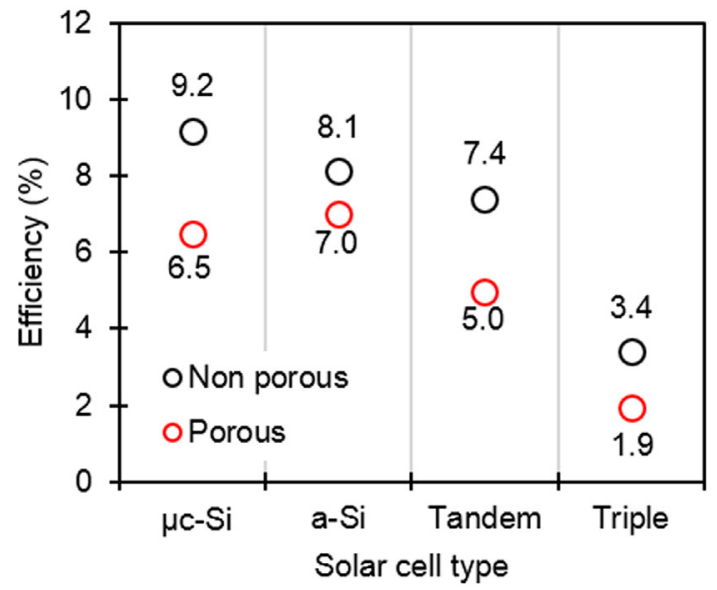

Fig. 5. Solar cell parameter values for non porous and porous cells and for various single-junction and multi-junction solar cell types.

the whole field towards a more coordinated activity. In particular, internationally accepted strategies were introduced, such as standard characterization methods and reporting certified efficiencies, as well as the adaptation of the device designs according to economy-related concepts such as the levelised cost of electricity. As a result, the highest PV efficiencies achieved [29], are closer to the theoretical upper limits than is the case in the solar water splitting field [28]. During this process of PV maturation, certain technologies had to fade out while the learning curve still continues through process simplifications for cost reduction [30], as well as optimisation based on the passage from the cell to the system level [31]. Similarly, in an effort to better coordinate the focus and the employed strategies for the solar water splitting field, instructions for benchmarking the methodologies and characterization procedure of solar fuel cells have been published [32]. Moreover, the use of consistent terminologies has been proposed [33], and an overview of the highest efficiency devices so far has been reported [8,34]. The learning curve of a mature field such as PV could be taken into consideration so as to target design concepts that have the highest potential to result in a technology breakthrough.

Device lifetime, efficiency and scalability (up-scaling) are three aspects which, if properly optimised, could lead to a technology breakthrough for the solar water splitting field. However, there is a clear compromise between the aforementioned figures and cost. As discussed by Dumortier et al. [35], the choice of device design requires a holistic approach with a simultaneous fulfilment of the aforementioned elements. In terms of device lifetime, most of the photoelectrodes in a PEC configuration suffer from degradation due to the chemical reactions which are taking place during the device operation. As highlighted by Ager et al. [34], the majority of device demonstrators so far have a very restricted stability ( $<1$ day). For that reason, solid state junctions are preferred over semiconductor/liquid junctions for longterm durable operation. Moreover, surface coatings have been developed for material protection during operation in extreme $p H$ values [36]. However, both solid state junctions and surface coatings increase the cost of the manufacturing process and should be taken into account during device design. Nonetheless, surface coatings have so far not resulted in device lifetimes comparable to PV (20-25 years), while slight changes in the electrolyte $p H$ (from 13 to 14) result in significant stability degradation even when solid state junctions are used [23]. Regarding efficiency, there is a clear compromise between expensive III-V and cost-effective silicon based materials [9]. However, from an analysis of various device configurations [35], it was shown that hydrogen could be produced at affordable prices in low cost systems with efficiencies around 6\%. Finally, up-scaling is one element that defines the potential for large-scale implementation of a certain technology as it strongly affects cost. So far, PEC device demonstrators are small scale while hydrogen and oxygen co-evolve in the same compartment without involving the use of membranes. For the specific case of monolithic integrated PEC devices, up-scaling is heavily obstructed due to high Ohmic losses in the electrolyte, as discussed earlier. 


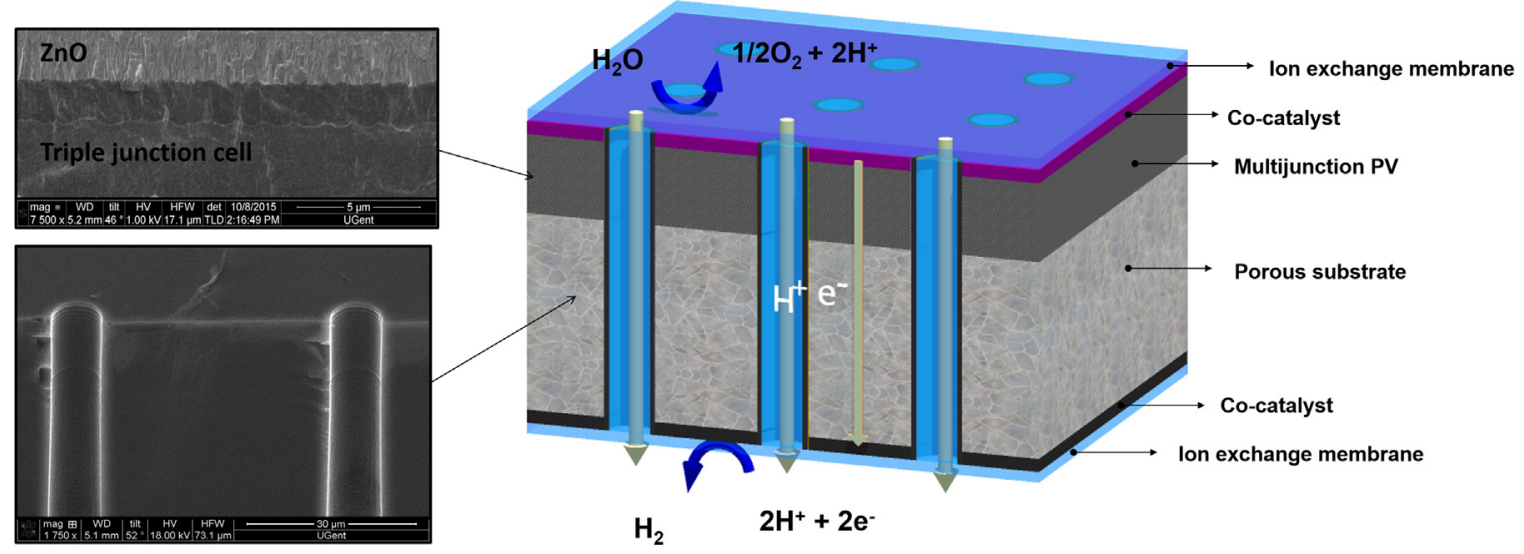

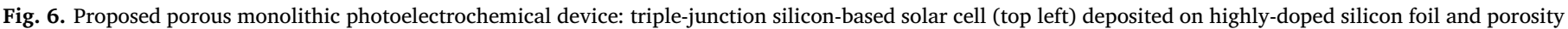
introduced by means of optical lithography and deep reactive ion etching (bottom left).

Following an interdisciplinary approach, taking into account the aforementioned aspects, we describe here an innovative approach for a porous monolithic PEC device. In Fig. 6, a schematic of the envisioned device is shown. Efficient and stable operation in a cost-effective fabrication can be provided by triple junction solar cells. Their performance parameters can be tuned in order to match the specific application of porous solar water splitting taking into account the device degradation during pore fabrication. In particular, a-Si cells are preferred compared to $\mu \mathrm{c}$-Si because of the minimal damage after the incorporation of the holes. Since the involved solar cells are based on the thin-film PV technology, their thickness is not sufficient for mechanical stability and therefore, one of the prerequisites of the envisioned device is the need of a conducting, porous but mechanically stable substrate. For that purpose, a highly conductive thin silicon foil could be used. Epitaxial foils have already been used for thin crystalline silicon solar cells [37]. The micron-scale porosity could be incorporated by means of low cost lithography in roll to roll configurations and deep reactive ion etching [38]. Additionally, by minimizing the overpotential related to the Ohmic losses in the electrolyte via the incorporation of holes/ shortcuts, an overpotential deficit could be afforded elsewhere in the device. More precisely, contrary to the state-of-the-art high efficiency devices which require expensive platinum group metals, earth-abundant catalysts such as NiMo and NiFe could be used for further cost reduction. Highly transparent catalysts and an ion exchange membrane should be employed at the front side. The ion exchange membrane should be thin enough to optimise gas transport and avoid parasitic absorption of light (absorption of light in materials which do not contribute to the photogenerated current and thus limit the device absorption and current generation) while it should be thick enough to optimise ion transport and diffusion limitations. At the rear side, a stack of relevant materials can be optimised for providing optical reflection of the incident light back into the photoactive materials and promoting the catalytic reaction. Overall, the conceptual device based on porous triple-junction silicon solar cells could offer a paradigm shift towards efficient, long -lasting and scalable devices targeting cost-effective implementation.

\section{Conclusion}

In this paper, we presented a novel design for scalable monolithic integrated solar water splitting. In particular, we discussed the concept of porous multi-junction solar cells. Silicon based multi-junction thinfilm solar cells could provide high STHE values in a low-cost fabrication and long durable operation while porosity would act as shortcuts for ions so as to maintain high STHE when up-scaled. On one hand, we have tried to investigate to what extent porosity has an impact on reducing overpotentials related to high Ohmic losses. Simulations show that dimensions on the order of a few tens to a few hundreds of $\mu \mathrm{m}$ could enable low ionic Ohmic losses. With such micro-scale pores, the electrochemical simulation indicate that one could potentially reach an efficiency of $11 \%$ at $p H=0.4 \%$ and $10.4 \%$ at $p H=2$ when combined with the best reported triple-junction solar cell. Additionally, by incorporating pores, we could relax the requirements for operation at extreme $\mathrm{pH}$ electrolytes which corrode the photoelectrodes limiting their lifetimes. On the other hand, we experimentally investigated the impact on the device operation when incorporating pores on singlejunction and multi-junction thin-film silicon solar cells. A square array of circular pores with a period of $100 \mu \mathrm{m}$ and a diameter of $20 \mu \mathrm{m}$ was fabricated by optical lithography and dry etching. Upon introduction of the micro-scaled pores to various silicon based solar cells, we experimentally demonstrated that there is only minimal decrease in $\mathrm{V}_{\text {oc }}$ (less than $10 \%$ relative difference). For our triple junction ( $\mu \mathrm{c}-\mathrm{Si}$ bottom /a$\mathrm{Si}$ middle/a-Si top) solar cell, we maintained a high $\mathrm{V}_{\text {oc }}$ of $1983 \mathrm{mV}$ after incorporating the pores. Given the fact that the impact is less pronounced on the a-Si compared to the $\mu \mathrm{c}-\mathrm{Si}$ cells, an all a-Si based triple junction solar cell deposited on a porous conductive carrier substrate (highly doped thin foil) could enable high solar to hydrogen efficiencies which can be maintained when upscaling. Such a device design offers a paradigm shift towards efficient, long -lasting and scalable devices.

\section{Acknowledgements}

This work was supported by the Research Foundation Flanders (FWO) via postdoctoral fellowships and the Flemish Government via long-term structural funding (Methusalem). The authors would like to thank S. Verstuyf for clean-room support and S. Haussener for fruitful discussions.

\section{References}

[1] J.H. Williams, A. DeBenedictis, R. Ghanadan, A. Mahone, J. Moore, W.R. Morrow III, S. Price, M.S. Torn, The technology path to deep greenhouse gas emissions cuts by 2050: the pivotal role of electricity, Science 335 (2012) 53-60.

[2] M.Z. Jacobson, M.A. Delucchi, Providing all global energy with wind, water, and solar power, Part I: technologies, energy resources, quantities and areas of infrastructure, and materials, Energy Policy 39 (2011) 1154-1169.

[3] B.V. Mathiesen, H. Lund, D. Connolly, H. Wenzel, P.A. Ostergaard, B. Moller, S. Nielsen, I. Ridjan, P. Karnoe, K. Sperling, F.K. Hvelplund, Smart energy systems for coherent 100\% renewable energy and transport solutions, Appl. Energy 145 (2015) 139-154.

[4] N.S. Lewis, Toward cost-effective solar energy use, Science 315 (2007) 798-801.

[5] K. Rajeshwar, R. McConnell, S. Licht, Solar Hydrogen Generation - Towards a Renewable Energy Future, Springer, New York, 2008.

[6] C.A. Grimes, O.K. Varghese, S. Ranjan, Light, Water, Hydrogen - the Solar Generation of Hydrogen by Water Photoelectrolysis, Springer, New York, 2008.

[7] M.G. Walter, E.L. Warren, J.R. McKone, S.W. Boettcher, Q. Mi, E.A. Santori, N.S. Lewis, Solar water splitting cells, Chem. Rev. 110 (2010) (64460-06473). 
[8] J. Rongé, T. Bosserez, D. Martel, C. Nervi, L. Boarino, F. Taulelle, G. Decher, S. Bordiga, J.A. Martens, Monolithic cells for solar fuels, Chem. Soc. Rev. 43 (2014) 7963-7981.

[9] O. Khaselev, A. Bansal, J.A. Turner, High-efficiency integrated multijunction photovoltaic/electrolysis systems for hydrogen production, Int. J. Hydrog. Energy 26 (2001) 127-132.

[10] F. Urbain, V. Smirnov, J.-P. Becker, U. Raw, J. Ziegler, B. Kaiser, W. Jaegermann, F. Finger, Application and modeling of an integrated amorphous silicon tandem based device for solar water splitting, Sol. Energy Mater. Sol. Cells 140 (2015) 275-280.

[11] S.Y. Reece, J.A. Hamel, K. Sung, T.D. Jarvi, A.J. Esswein, J.J.H. Pijpers, D.G. Nocera, Wireless solar water splitting using silicon-based semiconductors and earth-abundant catalysts, Science 334 (2011) 645-648.

[12] J. Newman, Scaling with Ohm's Law; wired vs. wireless photoelectrochemical cells, J. Electrochem. Soc. 160 (2013) F309-F311.

[13] T. Bosserez, L. Geerts, J. Ronge, F. Ceyssens, S. Haussener, R. Puers, J.A. Martens, Minimization of ionic transport resistance in porous monoliths for application in integrated solar water splitting devices, J. Phys. Chem. C. 120 (2016) 21242-21247.

[14] S. Haussener, C.X. Xiang, J.M. Spurgeon, S. Ardo, N.S. Lewis, A.Z. Weber, Modeling, simulation, and design criteria for photoelectrochemical water-splitting systems, Energy Environ. Sci. 5 (2012) 9922-9935.

[15] C. Xiang, Y. Chen, N.S. Lewis, Modeling an integrated photoelectrolysis system sustained by water vapor, Energy Environ. Sci. 6 (2013) 3713-3721.

[16] Comsol Inc, Comsol multiphysics 4.4, 2013.

[17] S. Wang, B.D. Weil, Y. Li, K.X. Wang, E. Garnett, S. Fan, Y. Cui, Large-area freestanding ultrathin single-crystal silicon as processable materials, Nano Lett. 13 (2013) 4393-4398.

[18] W. Yan, Z. Tao, M. Gu, B.S. Richards, Photocurrent enhancement of ultrathin fronttextured crystalline silicon solar cells by rear-located periodic silver nanoarrays, Sol. Energy 150 (2017) 156-160.

[19] Z. Yu, A. Raman, S. Fan, Nanophotonic light-trapping theory for solar cells, Appl. Phys. A 105 (2011) 329-339.

[20] S. Mokkapati, K.R. Catchpole, Nanophotonic light trapping in solar cells, J. Appl. Phys. 112 (2012) 101101-101119.

[21] C. Trompoukis, I. Abdo, R. Cariou, I. Cosme, W. Chen, O. Deparis, A. Dmitriev, E. Drouard, M. Foldyna, E. Garcia-Caurel, I. Gordon, B. Heidari, A. Herman, L. Lalouat, K.-D. Lee, J. Liu, K. Lodewijks, F. Mandorlo, I. Massiot, A. Mayer, V. Mijkovic, J. Muller, R. Orobtchouk, G. Poulain, P. Prod'Homme, P. Roca Cabarrocas, C. Seassal, J. Poortmans, R. Mertens, O. El Daif, V. Depauw, Photonic nanostructures for advanced light trapping in thin crystalline silicon solar cells, Phys. Status Solidi (a) 212 (2015) 140-155.

[22] M.A. Modestino, D. Fernandez Rivas, S.M.H. Hashemi, J.G.E. Gardeniers, D. Psaltis, The potential for microfluidics in electrochemical energy systems, Energy Environ. Sci. 9 (2016) 3381-3391.

[23] F. Urbain, V. Smirnov, J.-P. Becker, A. Lambertz, F. Yang, J. Ziegler, B. Kaiser, W. Jaegermann, U. Ray, F. Finger, Multijunction Si photocathodes with tunable photovoltages from $2.0 \mathrm{~V}$ to $2.8 \mathrm{~V}$ for light induced water splitting, Energy Environ. Sci. 9 (2016) 145-154.
[24] H. Sai, T. Matsui, T. Koida, K. Matsubara, M. Kondo, S. Sugiyama, H. Katayama, Y. Takeuchi, I. Yoshida, Stabilized 14.0\%-efficient triple-junction thin-film silicon solar cell, Appl. Phys. Lett. 106 (2015) 213902.

[25] M.T. Winkler, C.R. Cox, D.G. Nocera, T. Buonassisi, Modeling integrated photovoltaic-electrochemical devices using steady-state equivalent circuits, Proc. Natl. Acad. Sci. USA 110 (12) (2013) E1076-E1082, http://dx.doi.org/10.1073/pnas. 1301532110.

[26] C. Trompoukis, O. El Daif, P.P. Sharma, H.S. Radhakrishnan, M. Debucquoy, V. Depauw, K. Van Nieuwenhuysen, I. Gordon, R. Mertens, J. Poortmans, Passivation of photonic nanostructures for crystalline silicon solar cells, Prog. Photovolt. Res. Appl. 23 (2015) 734-742.

[27] J.-W. Schuttauf, B. Niesen, L. Lofgren, M. Bonnet-Eymard, M. Stuckelberger, S. Hanni, M. Boccard, G. Bugnon, M. Despeisse, F.-J. Haug, F. Meillaud, C. Ballif, Amorphous silicon-germanium for triple and quadruple junction thin-film silicon based solar cells, Sol. Energy Mater. Sol. Cells 133 (2015) 163-169.

[28] K.T. Fountaine, H.J. Lewerenz, H.A. Atwater, Efficiency limits for photoelec trochemical water-splitting, Nat. Commun. 7 (2016) 13706.

[29] M.A. Green, Y. Hishikawa, W. Warta, E.D. Dunlop, D.H. Levi, J. Hohl-Ebinger, A.W.H. Ho-Baillie, Solar cell efficiency tables (version 50), Prog. Photovolt. Res. Appl. 25 (2017) 668-676.

[30] L. Tous, S.N. Granata, P. Choulat, T. Bearda, A. Michel, A. Uruena, E. Cornagliotti, M. Aleman, R. Gehlhaar, R. Russel, F. Duerinckx, J. Szlufcik, Process simplifications in large area hybrid silicon heterojunction solar cells, Sol. Energy Mater. Sol. Cells 142 (2015) 66-74.

[31] J. Govaerts, T. Borgers, A. Van Der Heide, H. Goverde, M. Debucquoy, S. Dewallef, K. Baert, J. Szlufcik, J. PoortmansCell-to-module performance modeling: validation and application for advanced PV modules, in: Proceedings of the 31st European Photovoltaics Science and Engineering Conference, Hamburg, Germany, 2015. 1997-2000 DOI:10.4229/EUPVSEC20152015-5AV.6.21.

[32] Z. Chen, H.N. Dinh, E. Miller, Photoelectrochemical Water Splitting - Standards, Experimental Methods, and Protocols, Springer Briefs in Energy, Springer, New York, 2013.

[33] A.C. Nielander, M.R. Shaner, K.M. Papadantonakis, S.A. Francis, N.S. Lewis, A taxonomy for solar fuels generators, Energy Environ. Sci. 8 (2015) 16-25.

[34] J.W. Ager, M.R. Shaner, K.A. Walczak, I.D. Sharp, S. Ardo, Experimental demonstrations of spontaneous, solar-driven photoelectrochemical water splitting, Energy Environ. Sci. 8 (2015) 2811-2824.

[35] M. Dumortier, S. Tembhurne, S. Haussener, Holistic design guidelines for sola hydrogen production by photo-electrochemical routes, Energy Environ. Sci. 8 (2015) 3614-3628.

[36] R. Liu, Z. Zheng, J. Spurgeon, X. Yang, Enhanced photoelectrochemical watersplitting performance of semiconductors by surface passivation layers, Energy Environ. Sci. 7 (2014) 2504-2517.

[37] J. Govaerts, C. Trompoukis, H.S. Radhakrishnan, L. Tous, S.N. Granata, E.G. Carnemolla, R. Martini, A. Marchegiani, M. Karim, I. Sharlandziev, T. Bearda, V. Depauw, K. Van Nieuwenhuysen, I. Gordon, J. Szlufczik, J. Poortmans, Solar cells from epitaxial foils: an epifoil epiphany, Energy Procedia 77 (2015) 871-880.

[38] S.H. Ahn, L.J. Guo, High-speed roll-to-roll nanoimprint lithography on flexible plastic substrates, Adv. Mater. 9 (2008) 2044-2049. 